\title{
Validation of critical moisture conditions for mould growth on building materials
}

\author{
Pernilla Johansson*, Thomas Svensson, Annika Ekstrand-Tobin \\ SP Technical Research Institute of Sweden, Box 857, SE-501 15 Borås, Sweden
}

\section{A R T I C L E I N F O}

\section{Article history:}

Received 5 November 2012

Received in revised form

11 January 2013

Accepted 12 January 2013

\section{Keywords:}

Mould

Critical moisture level

Building material

Mould resistance

Crawl space

Attic

\begin{abstract}
A B S T R A C T
Materials that are stored or used in damp conditions may be subject to mould growth. However, all materials are not equally susceptible; for each specific material, there is a critical moisture level for mould growth. If this is exceeded, there is a risk that mould fungi will develop on the material. This level can be determined in accelerated laboratory tests, at constant temperatures and relative humidity (RH) favourable to mould growth. Within a building however, these parameters are expected to vary from one part of the construction to another, and are seldom constant; there is fluctuation in temperature and $\mathrm{RH}$ due to seasonal or shorter-term variations. In this study, test pieces of the same materials tested in a laboratory environment were placed in three outdoor ventilated crawl spaces and three outdoor ventilated attics, where the temperature and $\mathrm{RH}$ varied, and mould growth on the test pieces was studied over 2.5 years. Material-specific mould growth curves were produced based on critical moisture levels, as determined in laboratory experiments under constant temperature and $\mathrm{RH}$. When the actual conditions of RH and temperature exceeded these curves, there was mould growth on the test pieces if the time was sufficiently long. The conclusion from the study is that although conditions in laboratory studies are simplified and accelerated, the results serve well to indicate mould growth within a building construction.
\end{abstract}

(c) 2013 Elsevier Ltd. All rights reserved.

\section{Introduction}

Different parts of a building are exposed to different temperatures and relative humidity (RH), e.g. as a result of construction design and moisture produced by human activity. Materials used in construction are affected by the ambient conditions, and if these are favourable to mould fungi, there is a risk that mould will develop on the materials. However, all materials are not equally susceptible to mould growth. For each specific material, there is a critical moisture level for mould growth. If this is exceeded, there is a risk that mould fungi will develop on the material. Critical moisture conditions are also dependent on temperature. Mould fungi require more available water to grow at lower temperatures; consequently, critical moisture levels will be higher at lower temperatures than at higher temperatures.

The relationship between temperature, moisture and rate of growth on nutrient media in the laboratory has been described for a number of fungal species as isopleths, e.g. [1-3]. Some of these

\footnotetext{
* Corresponding author. Tel.: +46 105165150.

E-mail address: pernilla.johansson@sp.se (P. Johansson).
}

isopleths have been adapted to predict the risk of mould growth on building materials [4-6]. By calculating the expected conditions of a construction or part of a building, these limiting growth curves may be used to assess the risk of mould growth. These curves should also be based on critical moisture values and be material specific, since the value for one material cannot be used to predict the properties of another, although they may seem similar [7]. Also, different treatments of a material may alter resistance to mould growth [8].

Although there are optimal and minimal growth conditions for the different microfungi that are described as mould fungi, the organisms can survive periods of unfavourable conditions. How well they can tolerate fluctuating periods varies from species to species [9]. On building materials, the rate and extension of mould growth have been shown to be lower when favourable conditions alternate with less favourable [10]. In addition, how long these periods last is also of importance. In constructions, the conditions that building materials are exposed to are seldom constant; there are variations in both temperature and $\mathrm{RH}$. These variations can be long-term, such as seasonal variation, or shorter-term, due to human activity or local climatic conditions, for example. Therefore, the critical moisture level for a building material may be exceeded 
for a shorter or a longer period, while at other times the level may not favour mould growth. It is therefore expected that the risk of mould growth occurring is low if the variation is such that the moisture levels are substantially lower than the critical limits over a sufficiently long period and the critical limits are exceeded only for short periods of time.

Ventilated crawl spaces and attics are constructions where the temperature and $\mathrm{RH}$ are predominantly governed by outdoor conditions. There is therefore seasonal fluctuation in these structures. In Scandinavia, the RH in crawl spaces is highest in the summer and autumn when warm, moist outdoor air enters the cooler space. Since cold air can hold less moisture, the saturation moisture content is lower, and the RH will increase. In outdoor ventilated attics, however, the RH is usually at its highest during the winter months. There is also short-term variation, e.g. during clear nights when heat radiates from the roof to the sky, leading to a reduced temperature at the interior surface of the roof, which in turn enhances the risk of condensation and mould growth. In both crawl spaces and ventilated attics, there is often extensive mould growth on the building materials e.g. [11-13].

The purpose of this study was to investigate whether results from laboratory testing of materials for critical moisture levels in which constant conditions are maintained can predict mould growth in constructions where the temperature and RH fluctuate. The same materials that were tested in a laboratory environment [7] were placed in three outdoor ventilated crawl spaces and three outdoor ventilated attics. The development of mould on the test pieces was followed by analysing each test piece twice a year, in spring and autumn, over 2.5 years. Mould growth limit curves for the materials tested were produced based on known critical moisture levels and risk for mould growth in each construction were then expected if the $\mathrm{RH}$ and temperature exceeded these. Expected and observed growth was then compared.

Not all materials used in the study were intended to be used in crawl spaces and/or attics, but because the temperature and $\mathrm{RH}$ conditions of these constructions were expected to favour mould growth and the conditions expected to fluctuate, they were considered to be suitable test environments. In addition, the materials were readily available and could easily be evaluated for mould growth at the defined intervals.

\section{Materials and methods}

\subsection{Building materials}

Nine building materials (see Table 1) were purchased from a local building supply store. The materials are commonly used in
Swedish building construction sector, and have different critical moisture limits, as determined in an earlier laboratory study involving the same materials [7]. One material was asphalt paper, and the remaining eight were boards. Three individual boards of each type were used, and from each a single test piece, $50 \times 100 \mathrm{~mm}$, was prepared for exposure at each test site. For plywood and chipboard, an additional test specimen was prepared from two of the boards; consequently, there were five replicates of those materials. From the asphalt paper, all test pieces were prepared from one roll, and three pieces were placed at each test site. The choice of the number of test pieces was based on the number that are common in standardised methods for testing mould resistance of materials.

The test pieces were placed in stainless steel spring clips mounted on aluminium strips placed in the underlay roof of the attics and blind floor of the crawl spaces. The test pieces were easily dismantled from the clips for the analysis of microbial growth. All materials were handled in such a way (e.g. using plastic gloves) as to minimise risk of contamination that could have led to mould growth.

\subsection{Test-sites}

The houses where the test pieces were exposed were all singlefamily houses situated close to Borås in the south-west of Sweden. All these houses were buildings with light wooden framework structures and were representative of Swedish housing stock. They varied in construction year, heating system, construction design, building materials and other characteristics and were selected to represent constructions at both high and low risk of mould growth.

\subsubsection{House A: attic 1 and crawl space 1}

This house, the oldest in the study, was built in 1923. It was heated by a pellet boiler located in one of the outbuildings and a stove connected to the building's central chimney. The house roof was hipped, with a $45^{\circ}$ angle in the ridge. The roof material (from the outside inwards) comprised concrete tiles, thin hardboard and wooden rafters. The foundations were of stone; the floor of the crawl space was of soil and stone, and the height about $1 \mathrm{~m}$. The joists were insulated with approx. $10 \mathrm{~cm}$ of wooden chips.

\subsubsection{House B: attic 2 and crawl space 2}

House B was built in 1913 with a $40^{\circ}$ pitched roof. The materials in the roof were ceiling tiles, roofing felt, wooden rafters and secondary spaced boarding. The house was in a half plane with a crawl

Table 1

Building materials used in the study.

\begin{tabular}{|c|c|c|c|}
\hline \multirow[t]{2}{*}{ Building material } & \multirow[t]{2}{*}{ Description } & \multicolumn{2}{|c|}{$\begin{array}{l}\text { Range in which the critical moisture level is expected } \\
\text { (Johansson et al., unpublished results) }\end{array}$} \\
\hline & & $22{ }^{\circ} \mathrm{C}$ & $10^{\circ} \mathrm{C}$ \\
\hline Pine sapwood & $19 \mathrm{~mm}$ tongued and grooved board & $75<\mathrm{RH}_{\text {crit }} \leq 79$ & $85<\mathrm{RH}_{\text {crit }} \leq 90$ \\
\hline Plywood & 12 mm softwood plywood & $75<\mathrm{RH}_{\text {crit }} \leq 79$ & $85<\mathrm{RH}_{\text {crit }} \leq 90$ \\
\hline Chipboard & $12 \mathrm{~mm}$ particle board & $79<\mathrm{RH}_{\text {crit }} \leq 85$ & $90<\mathrm{RH}_{\text {crit }} \leq 93$ \\
\hline Thin hardboard & $\begin{array}{l}3.2 \mathrm{~mm} \text { high density hardboard made of wood fibres } \\
\text { and lignin }\end{array}$ & $85<\mathrm{RH}_{\text {crit }} \leq 89$ & $93<\mathrm{RH}_{\text {crit }} \leq 95$ \\
\hline Wet-room gypsum plaster & $13 \mathrm{~mm}$ gypsum board with cardboard surfaces & $89<\mathrm{RH}_{\text {crit }} \leq 95$ & $95<\mathrm{RH}_{\text {crit }}$ \\
\hline Exterior gypsum plaster & $13 \mathrm{~mm}$ gypsum board with cardboard surfaces & $89<\mathrm{RH}_{\text {crit }} \leq 95$ & $95<\mathrm{RH}_{\text {crit }}$ \\
\hline Asphalt paper & $\begin{array}{l}1.5 \mathrm{~mm} \text { windproof barrier of asphalt-impregnated cellulose } \\
\text { paper }\end{array}$ & $89<\mathrm{RH}_{\text {crit }} \leq 95$ & $95<\mathrm{RH}_{\text {crit }}$ \\
\hline Cement-based board & $\begin{array}{l}8 \mathrm{~mm} \text { cement based board consisting of cement, } \\
\text { limestone and cellulose fibres, covered with a plastic dispersion }\end{array}$ & $95<\mathrm{RH}_{\text {crit }}$ & $95<\mathrm{RH}_{\text {crit }}$ \\
\hline Glassfibre board & $15 \mathrm{~mm}$ rigid glass wool insulation board & $95<\mathrm{RH}_{\text {crit }}$ & $95<\mathrm{RH}_{\text {crit }}$ \\
\hline Expanded polystyrene board & $50 \mathrm{~mm}$ expanded polystyrene insulation board & $95<\mathrm{RH}_{\text {crit }}$ & $95<\mathrm{RH}_{\text {crit }}$ \\
\hline
\end{tabular}


space under two-thirds of the house. The remainder consisted of laundry room and boiler room. Heating was by pellet boiler. The foundations were of stone; the floor of the crawl space was of soil and stone; and the height about $0.5 \mathrm{~m}$. The joists were insulated with approx. $10 \mathrm{~cm}$ of wooden chips.

\subsubsection{House C: crawl space 3}

This house was built around 1980. There was a crawl space under two-thirds of the house. The remaining one-third consisted of a cellar including laundry and boiler room. The house was heated from a wood furnace in this basement. The crawl space section, where the test was carried out, was ventilated with outdoor air and unheated. The foundations were of concrete blocks, and the floor of the crawl space was crushed rock/gravel. The joists were insulated with mineral wool insulation.

\subsubsection{House D: attic 3}

This $1 \frac{1}{2}$-storey house was built in 1982 and had a $45^{\circ}$ pitched roof. At the beginning of the project, heating was provided by direct electricity, but this was replaced after a year or so by an air-water heat pump, though distribution via water was the same throughout the test period. Throughout the investigation, fires were frequently lit in a centrally located wood-burning stove. The roof was built, from the outside inwards, of concrete tiles, roofing felt, roof trusses and hard fibre board.

\subsection{Measurement of temperature and $\mathrm{RH}$ at the test-sites}

Temperature and $\mathrm{RH}$ at each test-site were registered every fourth hour by a single data logger with internal sensors (Testo 177$\mathrm{H} 1$ ). Each logger was placed in close proximity to the specimens to ensure that the conditions logged were as close as possible to those that specimens were exposed to.

The sensors were initially calibrated at $30.1{ }^{\circ} \mathrm{C}$ over three aqueous saturated salt solutions, with reference values of $83.6 \%$, $92.3 \%$ and $75.1 \%$. After exposure in the field, a new calibration was performed in moisture chambers with a calibrated reference moisture and humidity sensor at temperatures of $22^{\circ} \mathrm{C}$ and $15{ }^{\circ} \mathrm{C}$ and $\mathrm{RH}$ of $90 \%, 85 \%$ and $60 \%$. The calibration made it possible to adjust the measured $\mathrm{RH}$ values with the correction factor from calibration (reference minus measured $\mathrm{RH}$ ). However, since this factor was expected to be dependent on temperature [14], and the temperature and $\mathrm{RH}$ were not constant in the field measurements, the second calibration procedure made it possible to apply a more accurate adjustment of data. A multiple regression was performed in which both temperature and $\mathrm{RH}$ were included. Each sensor was then given an equation which was used to adjust the measured values.

Comparing the results of $\mathrm{RH}$ from the initial and final calibrations, it was concluded that all sensors had drifted, to various extents, so that they showed higher values after exposure than before exposure in the field. The measured values were therefore further adjusted. For each logger, the drift, which was assumed to be constant during the exposure period, was estimated by calculating the difference between the calibration errors before and after measurement in the field. By dividing this difference by the total number of times measurements were taken (which was about 5500 , i.e. six times each day for 2.5 years), we obtained a value for the drift at each logged time. We called this the "drift factor". The actual value of the $\mathrm{RH}$ at each time point was calculated for each sensor, using the equation obtained from the multiple regression based on the final calibration, complemented by an adjustment with the service drift factor multiplied by the successive number of the time point.
$\mathrm{RH}_{\text {adjusted }}=a_{i}+b_{i} * \mathrm{RH}_{\text {instrument }}+c_{i} * t_{\text {instrument }}-\gamma * T[\%]$

where

$a_{i}, b_{i}, c_{i}$ - Parameters from the multiple regression for each logger $i$

$\mathrm{RH}_{\text {instrument }}$ - measured $\mathrm{RH}(\%)$

$t_{\text {instrument }}-$ measured temperature $\left({ }^{\circ} \mathrm{C}\right)$

$\gamma$ - drift factor-error due to the drift at each measuring point

$T-$ The number of the measuring point

The expanded uncertainty for each sensor was calculated by considering the variance of the multiple regression together with the uncertainty of the reference sensor and the measurement uncertainty for the calibration. The uncertainty of drift can be considered negligible since it was very small in comparison.

\subsection{Analysis of mould growth on test pieces}

Every April and October, i.e. five occasions in all, the test pieces were removed from the racks where they were exposed; they were then analysed for mould growth. The surface that had been exposed to the open air in the attics and crawl spaces was examined at $10 \times-40 \times$ magnification under the microscope. Both mould growth visible to the naked eye and that which was only visible under the microscope were rated according to a five-point rating scale, where $0=$ no growth; 1 = sparse, initial growth with only one or a few hyphae present; 2 = sparse but clearly established growth; 3 = patchy, heavy growth; and 4 = growth over most or all of the surface. A test piece was considered to have failed when the rating of mould growth first reached 2 or higher, we define this as when mould growth was clearly established [7].

\subsection{Description of mould growth with time}

The percentage of test pieces that were not failed (3.4) at each analysis time was expressed as Kaplan-Meier curves. This is an approach that has many advantages [15]. On each occasion that a test piece failed, the percentage of test pieces without no mould growth decreased.

\subsection{Creation of mould growth limit curves}

To create growth limit curves for each material, we used the same technique as Hofbauer et al. [16], where material-specific isopleths were constructed from the closest approximation to LIM 0 curve for mycelial growth [5].

As the equation for the LIM 0 curve had not been published at the time of our study, we carried out curve fitting to obtain parameters for such an equation. We then fitted data from this curve to a polynomial of second degree. This contains three parameters, but in order to simplify the model we wanted only two parameters. In order to be able to get such an equation, we fixed a function minimum at a defined temperature. We chose $27^{\circ} \mathrm{C}$. This value was based on the observation that, for many species of mould fungi, the temperature at which the required water availability is at minimum, i.e. the optimum temperature, is between $25^{\circ} \mathrm{C}$ and $30^{\circ} \mathrm{C}$ [3]. Above and below this temperature, the moisture requirements are higher, as described by the isopleths for each species. For the species used in the laboratory tests that formed the basis for the critical moisture levels for the materials in this study, the optimum temperature according to Sedlbauer [5] lies between $22^{\circ}$ and $30^{\circ} \mathrm{C}$, with a mean value of $27^{\circ} \mathrm{C}$. However, testing with different values of min temperature revealed that the model was not sensitive for 
which value between $25{ }^{\circ} \mathrm{C}$ and $30{ }^{\circ} \mathrm{C}$ that were used in the temperature range between $0{ }^{\circ} \mathrm{C}$ and $30^{\circ} \mathrm{C}$.

The resulting growth limit curve model can then be described by Equation (2):

$\mathrm{RH}=a+c\left(t^{2}-54 * t\right)[\%]$

where $t$ is the temperature in ${ }^{\circ} \mathrm{C}$.

The parameters $c$ and $a$ were estimated by using Equations (3) and Equation (4), where the data for RFcrit and corresponding temperature come from the results in the laboratory tests [7], Table 1:

$$
\begin{aligned}
& c=\left(\mathrm{RH}_{\text {crit1 }}-\mathrm{RH}_{\text {crit2 }}\right) /\left(t_{1}^{2}-t_{2}^{2}-54\left(t_{1}-t_{2}\right)\right) \\
& a=\mathrm{RH}_{\text {crit } 1}-c\left(t_{1}^{2}-54 * t_{1}\right)
\end{aligned}
$$
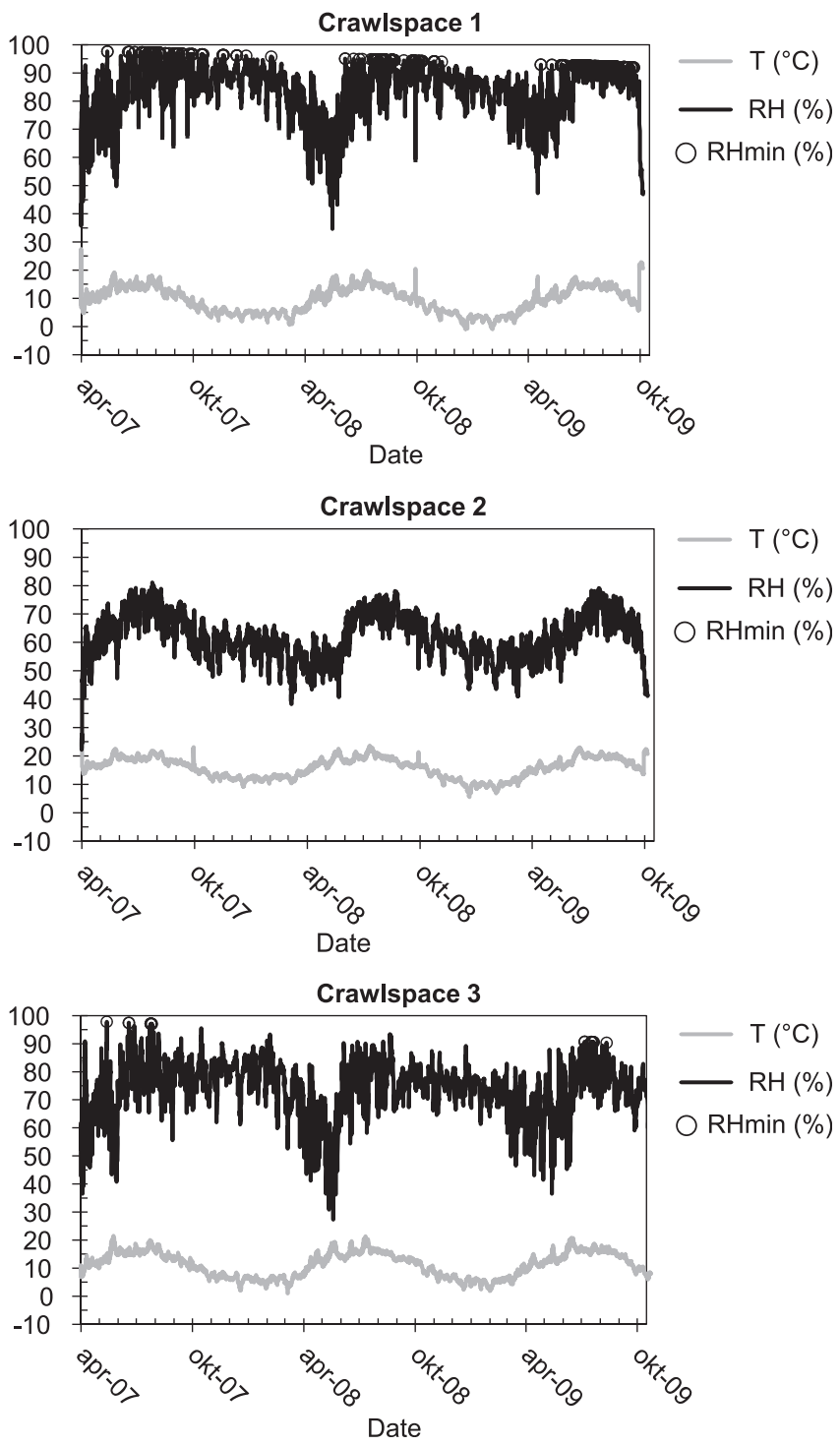

Fig. 1. Monitored relative humidity and temperature in three crawl spaces in Sweden. Values marked " $\mathrm{RH}_{\min }$ " refer to data where the drift of the loggers was such that the correct value could not be estimated. The specified dates refer to when microbiological analyses were performed.
Two growth limit curves, one upper and one lower, were produced for each material. The laboratory tests were carried out in test chambers with constant $\mathrm{RH}$, with $\mathrm{RH}$ set at intervals of $5 \%$; therefore the critical moisture level fell within a range. The upper limit was determined by the case with lowest RH where any of the above criteria were met, and the lower limit by the case with the next-lowest RH. The actual critical moisture level may therefore lie between the two growth limit curves, or above the upper curve [16].

\subsection{Comparison of results from laboratory and field studies}

In order to find out if the conditions in the test-sites had exceeded the growth limit curves, these were drawn into plots of monitored temperature and RH. Mould growth was then expected when the combination of temperature and RH exceeded the growth limit curves [4]. This expected growth was then compared to the results from the assessment of mould growth on the test pieces at each test site.
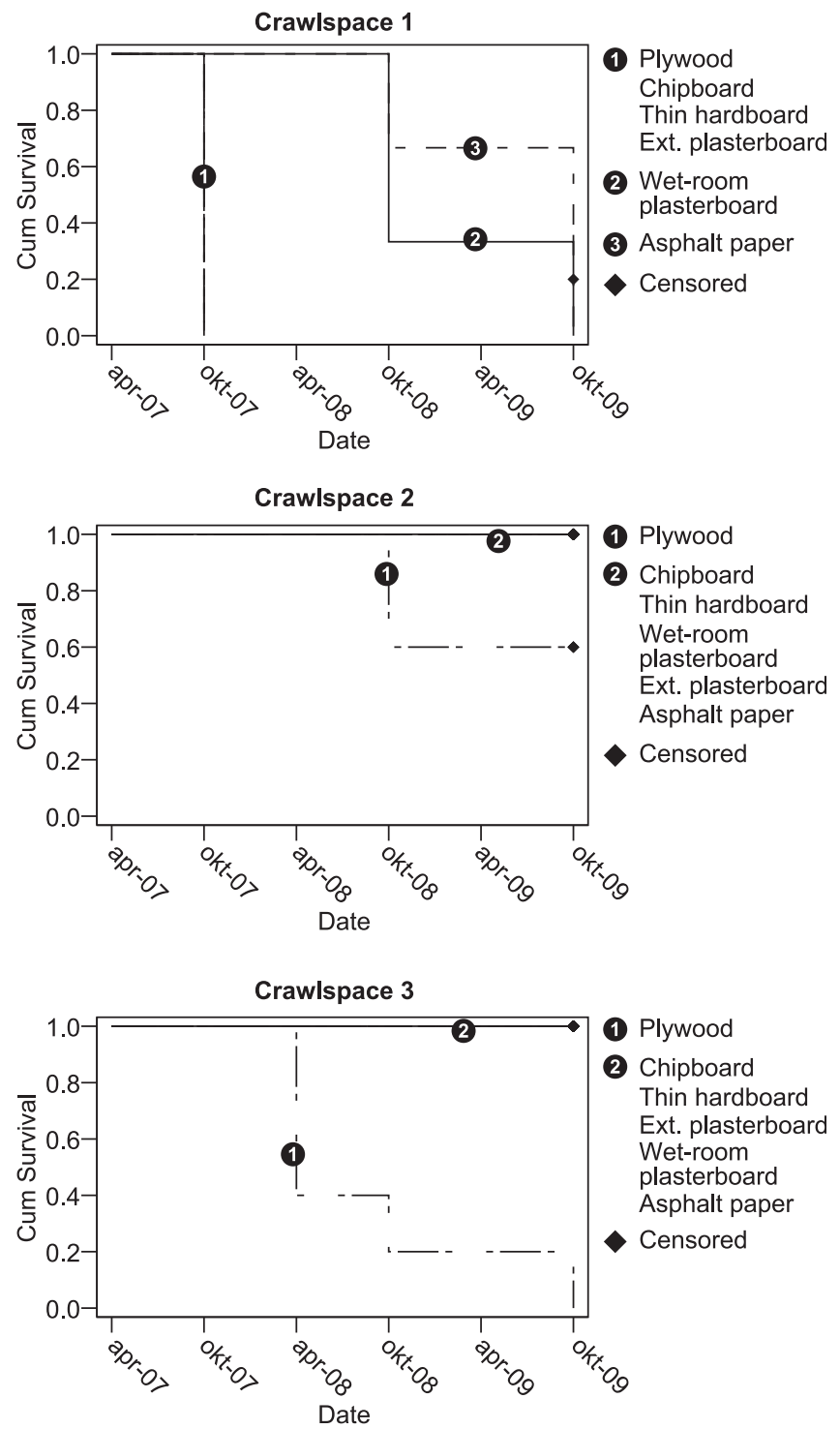

Fig. 2. Proportion of test pieces of six building materials, exposed to conditions in three crawl spaces, with no established growth at different times of analysis. 
In those cases where expected and observed mould growth was not consistent, the number of occasions on which the relevant growth limit curves were exceeded was counted. Each measurement point was then regarded as constant for four hours because temperature and $\mathrm{RH}$ were logged at this interval. The cumulative time was calculated as the sum of these hourly values. If the time was shorter than the shortest time before the critical moisture level was achieved in the laboratory, no growth was expected.

\subsection{Prediction of critical moisture levels for different temperatures}

Testing to find the critical moisture level must be carried out at several RHs, and, to predict the risk at different temperatures according to Section 2.6 above, at two temperatures, at least. This entails extensive testing in practice. One way to make the test feasible is to test at one temperature and to predict the expected critical moisture level at other temperatures. In such case, the parameter or $c$ needs to be known. Based on the values of $a$ that were estimated for each material in the study, an average was
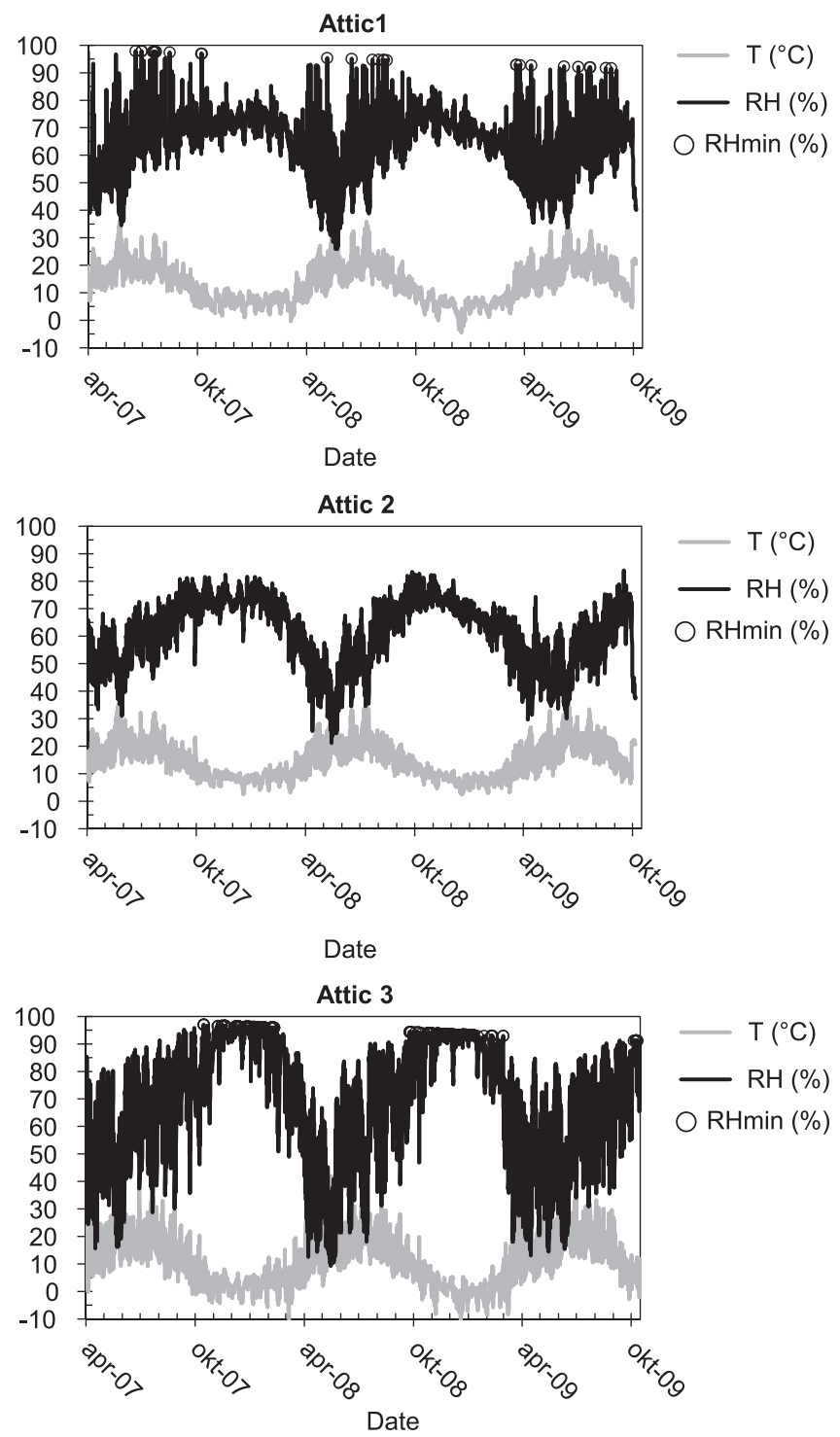

Fig. 3. Monitored relative humidity and temperature in three attics in Sweden. Values marked " $\mathrm{RH}_{\min }$ " refer to data where the drift of the loggers was such that the correct value could not be estimated. The specified dates refer to when microbiological analyses were performed. therefore calculated and then used to calculate parameter $c$ for each material. New growth limit curves could then be created in accordance with Equation (2). The difference between the two curves obtained in this way for each material was then assessed.

\section{Results}

The temperature and RH measurements from April 2007 to October 2009 are presented in Figs. 1 and 3. Variation during the day was greatest in the attics, with the $\mathrm{RH}$ being highest during the cold months of the year, when the temperature was also lowest. In the crawl spaces, however, RH was highest in the summer. Measurement uncertainty for $\mathrm{RH}$ was maximum $2 \%$ for each location.

Mould grew on several of the test pieces. However, among the sites, we observed differences in which materials became mouldy, how quickly growth arose and the extent of growth at test pieces at each site. Figs. 2 and 4 present the percentage of test pieces that had not failed, that is had no established mould growth on them, at each analysis time. Pieces that did not fail during the entire test period were censored in the plots. Table 2 presents the number of test pieces with established growth at the end of the test. No growth was observed on any of the test pieces of cement-based board, glass fibre board or expanded polystyrene board. No growth was observed on any of the test pieces in Attic 2.

Figs. 5 and 6 show the limit curves for mould growth for each material, together with the measured data of temperature and $\mathrm{RH}$ for each test site. Measured RH is plotted against measured temperature, each point corresponding to one measurement. If points were above the limit lines, growth was expected on the test pieces. Table 3 compares the results expected under this criterion with actual observations of growth on the test pieces at the end of the field study. Limit curves for growth were not produced for cementbased board, glass fibre board or expanded polystyrene board, since mould did not grow on any of these materials in any of the tests in
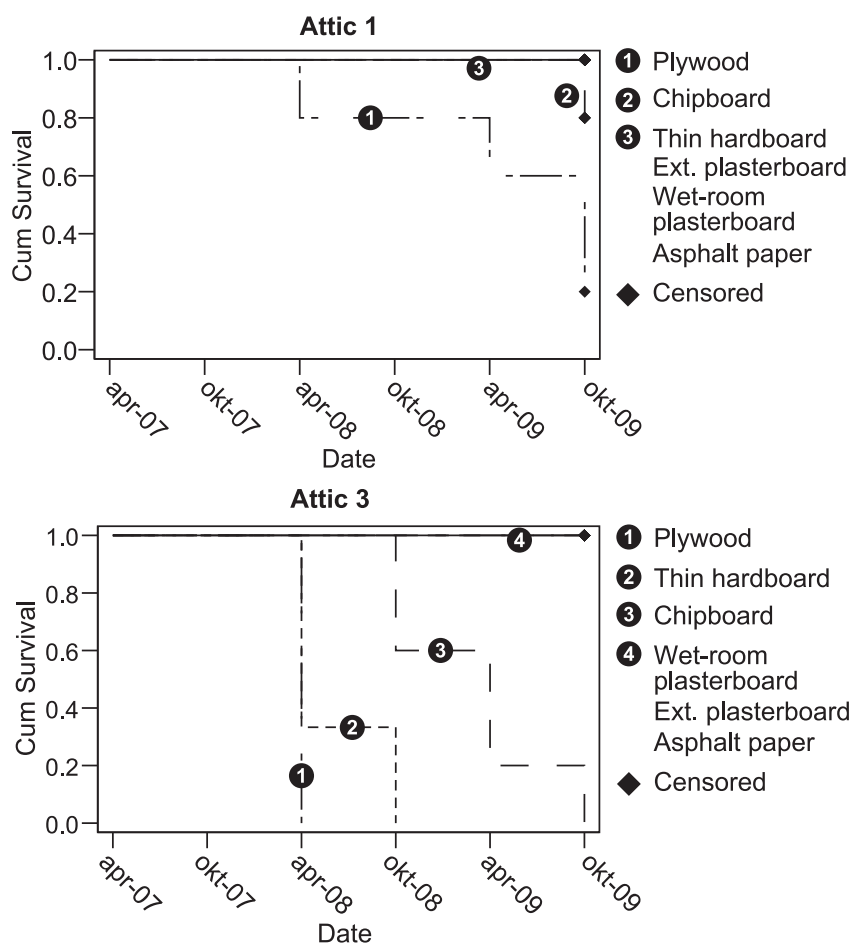

Fig. 4. Proportion of test pieces of six building materials, exposed to conditions in three attics, with no established growth at different times of analysis. In Attic 2 there was no growth on any of the test specimens during the test period. 
Table 2

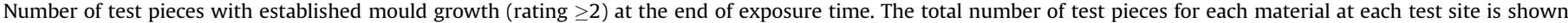
between the parentheses in the heading.

\begin{tabular}{|c|c|c|c|c|c|c|c|c|c|}
\hline & $\begin{array}{l}\text { Chipboard } \\
(N=5)\end{array}$ & $\begin{array}{l}\text { Plywood } \\
(N=5)\end{array}$ & $\begin{array}{l}\text { Thin hardboard } \\
(N=3)\end{array}$ & $\begin{array}{l}\text { Wet room plaster } \\
\text { board }(N=3)\end{array}$ & $\begin{array}{l}\text { Exterior plaster } \\
\text { board }(N=3)\end{array}$ & $\begin{array}{l}\text { Expanded poly-styrene } \\
\text { (EPS) board }(N=3)\end{array}$ & $\begin{array}{l}\text { Asphalt paper } \\
(N=3)\end{array}$ & $\begin{array}{l}\text { Glass fibre } \\
\text { board }(N=3)\end{array}$ & $\begin{array}{l}\text { Cement based } \\
\text { board }(N=3)\end{array}$ \\
\hline Crawl space 1 & 5 & 5 & 3 & 3 & 3 & 0 & 3 & 0 & 0 \\
\hline Crawl space 2 & 0 & 2 & 0 & 0 & 0 & 0 & 0 & 0 & 0 \\
\hline Crawl space 3 & 0 & 5 & 0 & 0 & 0 & 0 & 0 & 0 & 0 \\
\hline Attic 1 & 1 & 4 & 0 & 0 & 0 & 0 & 0 & 0 & 0 \\
\hline Attic 2 & 0 & 0 & 0 & 0 & 0 & 0 & 0 & 0 & 0 \\
\hline Attic 3 & 5 & 5 & 3 & 0 & 0 & 0 & 0 & 0 & 0 \\
\hline
\end{tabular}

a

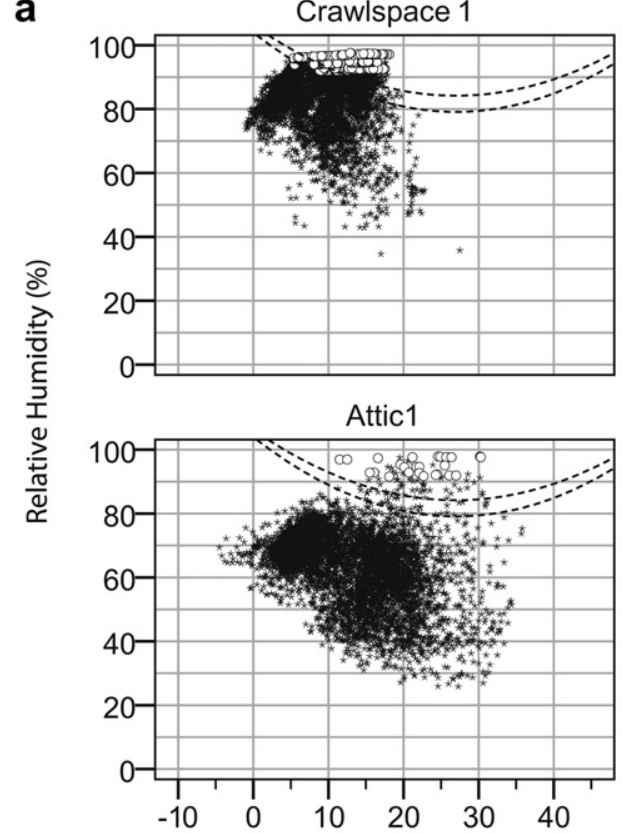

Crawlspace 2

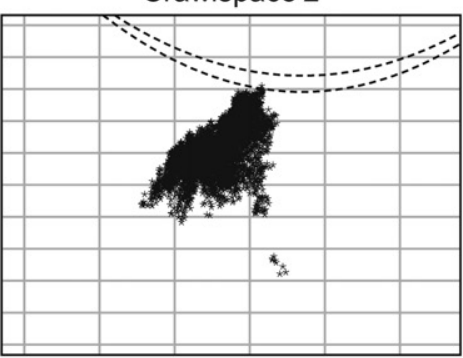

Attic 2

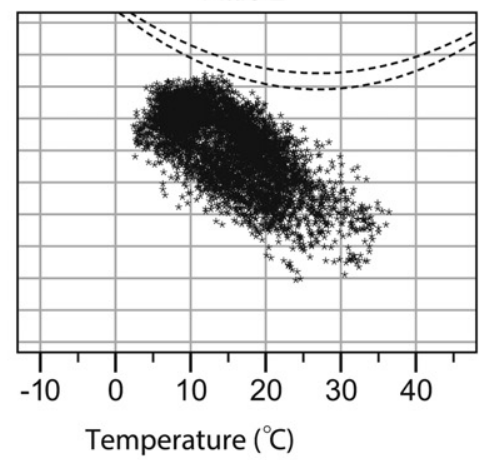

Temperature $\left({ }^{\circ} \mathrm{C}\right)$

b

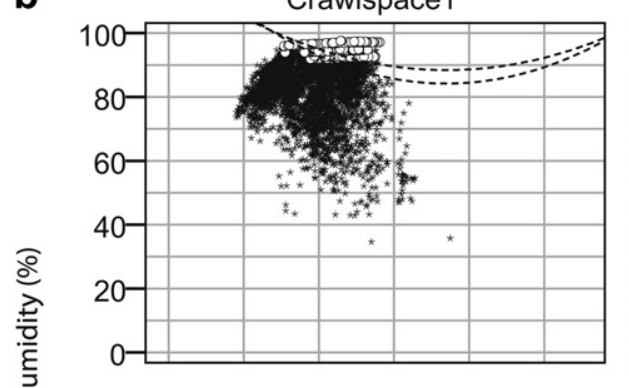

Attic1

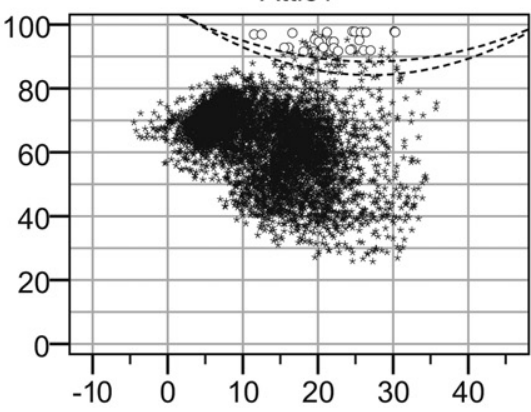

Crawlspace 2

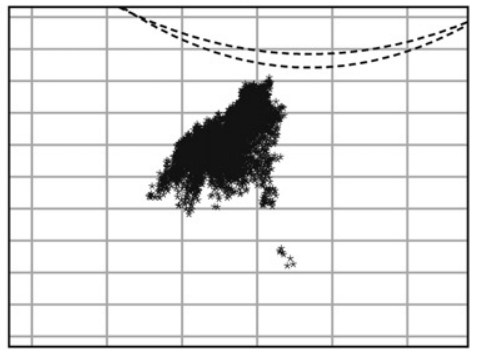

Attic 2

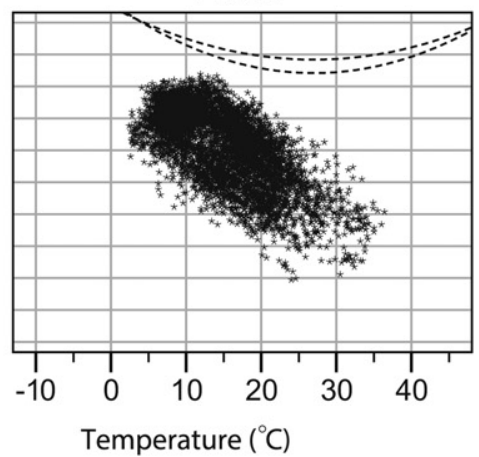

Crawlspace 3

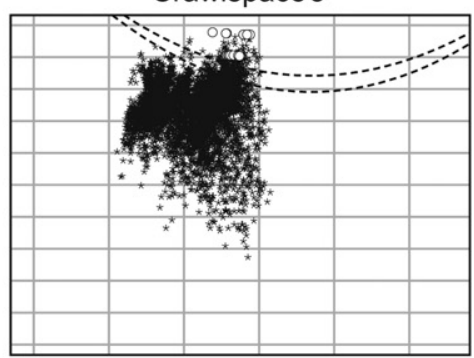

Attic 3

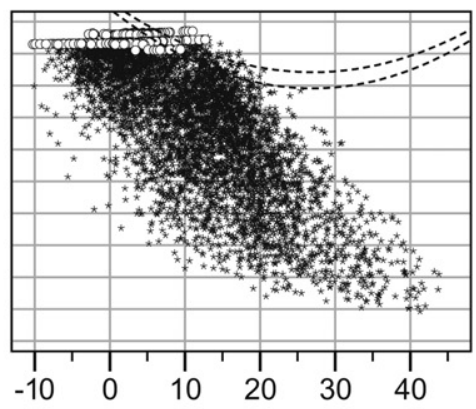

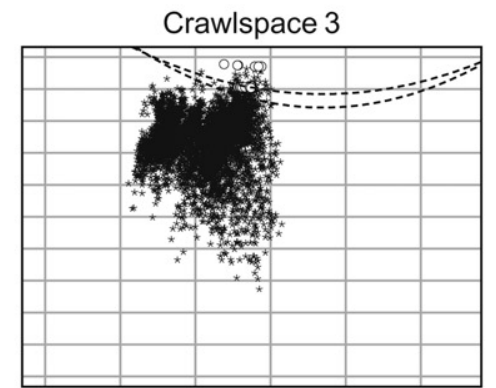

Attic 3

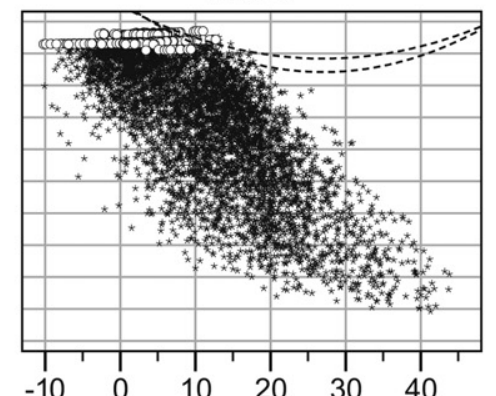

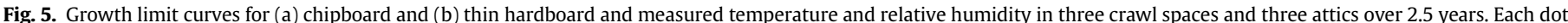

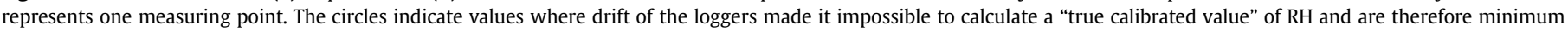
values. The dotted lines are the lower and upper growth limit curves estimated from results in laboratory tests. 
a

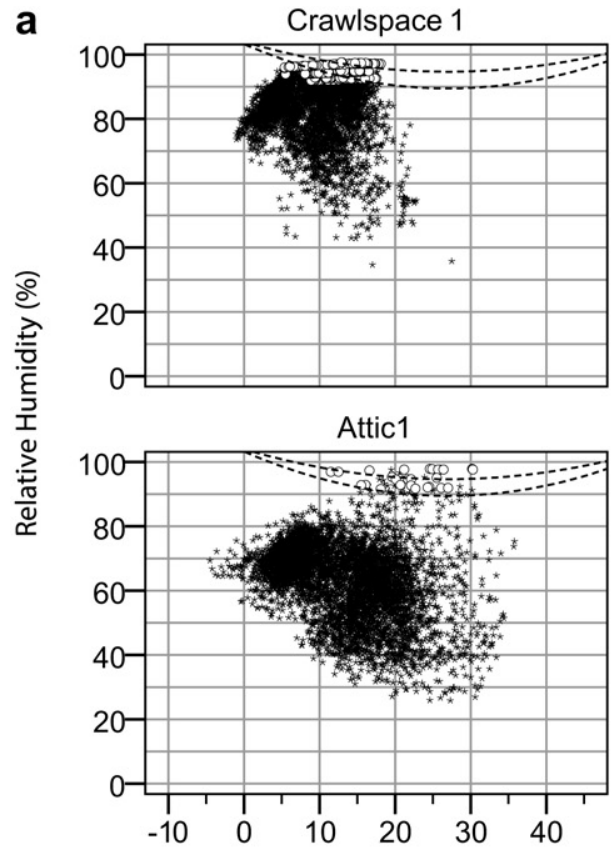

b
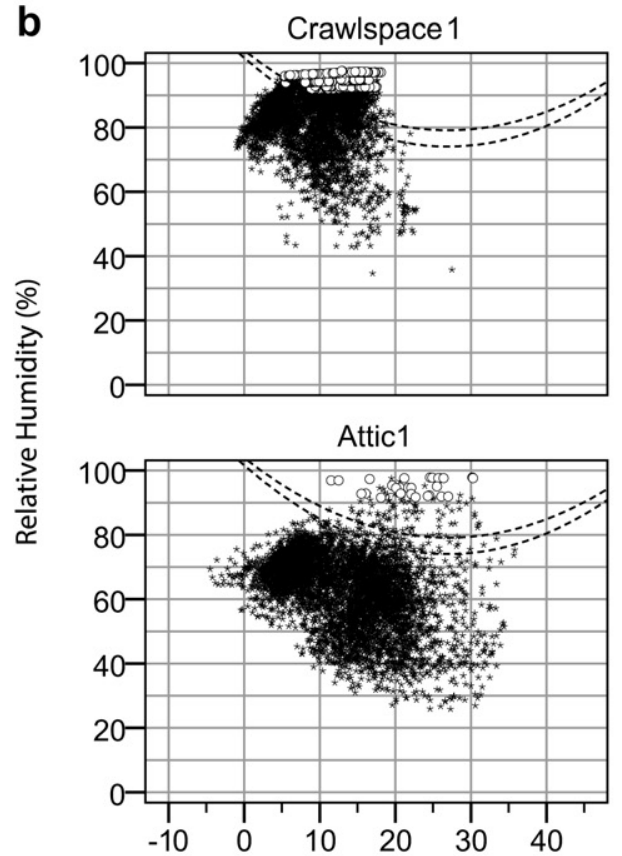

Crawlspace 2

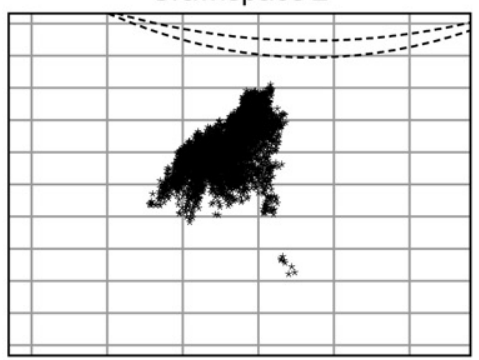

Attic 2

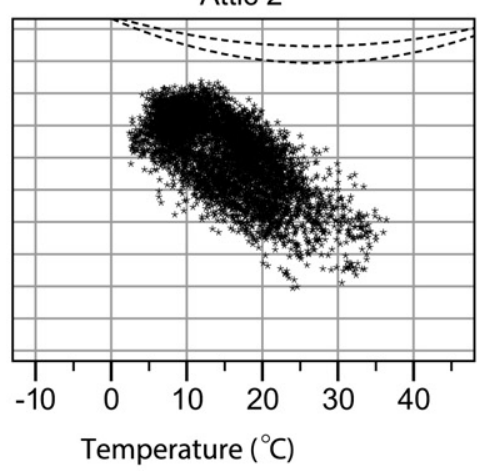

Crawlspace 2

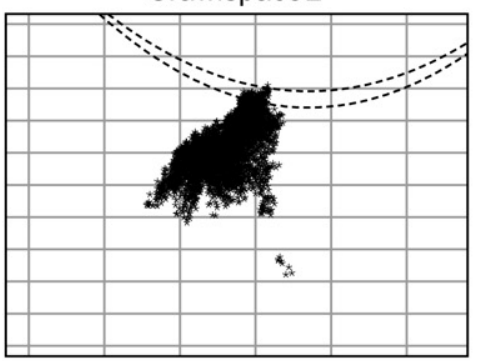

Attic 2

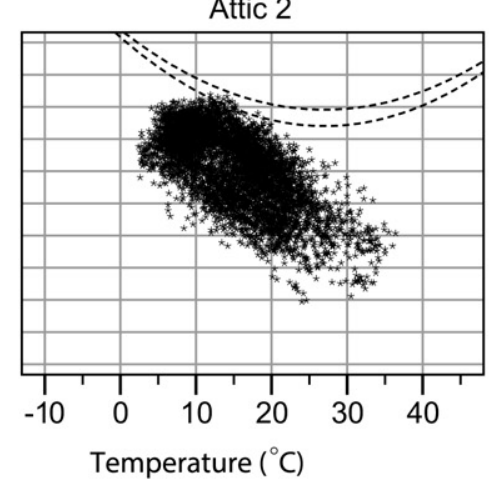

Crawlspace 3

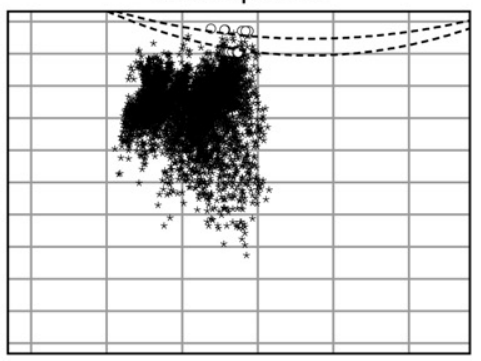

Attic 3

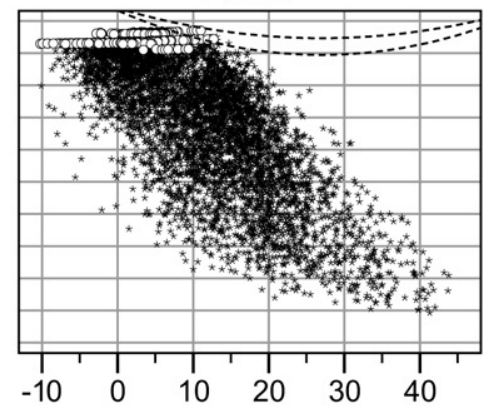

Crawlspace 3

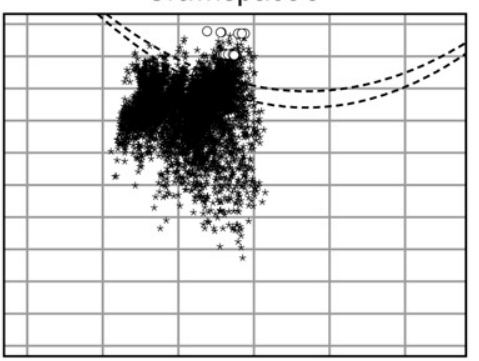

Attic 3

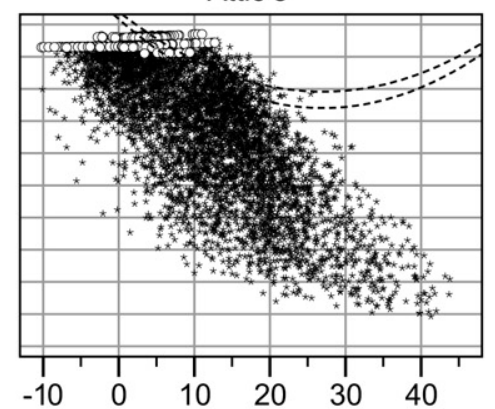

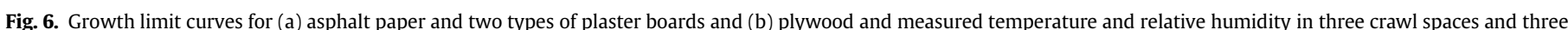

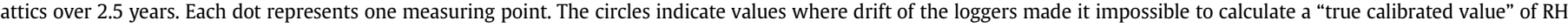
and are therefore minimum values. The dotted lines are the lower and upper growth limit curves estimated from results in laboratory tests.

the laboratory and the critical moisture level could not be estimated and/or the materials were resistant to mould growth.

Table 4 shows the total time that the temperature and $\mathrm{RH}$ were over the limit curves for those cases where expected and actual mould growth were not consistent; it also shows the time when the critical moisture level was achieved in the laboratory experiments. Since these analyses were carried out once a week, time is reported as an interval.

There was consistency between actual and expected mould growth when both criteria - (a) conditions exceeding the limits for growth and (b) cumulative time over the limits being lower than the time before mould growth were established in the laboratory were considered.

From the laboratory tests, six mould growth curves (see Section 2.5 ) were calculated. The upper curve of one material was sometimes the same as the lower curve of another. For the nine materials tested, there were therefore a total of six such limit curves, with values of $a$ ranging from 102 to 108 , with a mean of 105 . New growth curves with this value were produced and compared to those produced with individual values. Fig. 7 shows an example of 
Table 3

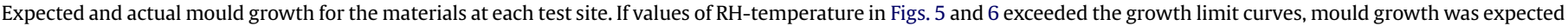

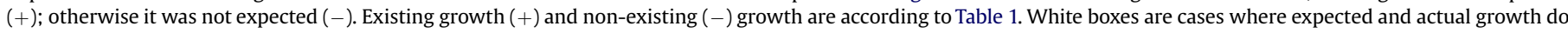
not agree based on these criteria.

\begin{tabular}{|c|c|c|c|c|c|c|c|c|c|c|c|c|}
\hline & \multicolumn{2}{|c|}{ Crawl space 1} & \multicolumn{2}{|c|}{ Crawl space 2} & \multicolumn{2}{|c|}{ Crawl space 3} & \multicolumn{2}{|l|}{ Attic 1} & \multicolumn{2}{|l|}{ Attic 2} & \multicolumn{2}{|l|}{ Attic 3} \\
\hline & Expected & Existing & Expected & Existing & Expected & Existing & Expected & Existing & Expected & Existing & Expected & Existing \\
\hline Plywood & + & + & + & + & + & + & + & + & + & - & + & + \\
\hline Chipboard & + & + & - & - & + & - & + & + & - & - & + & + \\
\hline Thin hardboard & + & + & - & - & + & - & + & - & - & - & + & + \\
\hline Exterior gypsum paper board & + & + & - & - & + & - & + & - & - & - & + & - \\
\hline Wet room gypsum paper board & + & + & - & - & + & - & + & - & - & - & + & - \\
\hline Asphalt paper & + & + & - & - & + & - & + & - & - & - & + & - \\
\hline Cement-based board & $-{ }^{a}$ & - & $-{ }^{a}$ & - & $-{ }^{\mathrm{a}}$ & - & $-{ }^{a}$ & - & $-{ }^{\mathrm{a}}$ & - & $-{ }^{a}$ & - \\
\hline Glassfibre board & $-{ }^{a}$ & - & $-{ }^{a}$ & - & $-{ }^{\mathrm{a}}$ & - & $-{ }^{a}$ & - & $-{ }^{\mathrm{a}}$ & - & $-{ }^{\mathrm{a}}$ & - \\
\hline Expanded polystyrene board & $-{ }^{a}$ & - & $-{ }^{a}$ & - & ${ }^{\mathrm{a}}$ & - & $-{ }^{a}$ & - & $-{ }^{a}$ & - & $-{ }^{a}$ & - \\
\hline
\end{tabular}

a This is based on the findings that there was no mould growth on any of the test pieces in the laboratory.

growth limit curves for the value estimated for the relevant material together with a curve were the value of $a$ was 105 . The maximum difference between these two curves, in this case for chipboard, is two percentage points for $\mathrm{RH}$ in the $0^{\circ}-40^{\circ} \mathrm{C}$ interval, and one percentage point in the $10^{\circ}-22^{\circ} \mathrm{C}$ interval. These values are similar for all materials tested.

\section{Discussion}

In this study, expected mould growth on building materials, based on laboratory studies of criteria for critical moisture levels, was compared with actual results on test pieces exposed in crawl spaces and attics. If the temperature and relative humidity conditions exceeded the limits for growth, then mould growth was expected. Length of time above the critical level is also significant. When both of these criteria were taken into account, the consistency between expected and actual mould growth was good.

The number of test pieces of each material at each test site was relatively low (three to five). After the start of the study, we found that in order to obtain a sufficient level of confidence in the assessment, the appropriate number of test pieces for assessment of mould growth was at least seven [7]. With a large expected variation among different test pieces of the same material, the number of test pieces should be as large as possible. After exposure for 2.5 years, however, little variation was found; in 10 of 13 cases where growth was observed, mould grew on all test pieces of the tested materials at each site (see Table 2). The number of test pieces was too small to make a correct Kaplan-Meier estimation; Figs. 2 and 4 therefore should be considered empirical data.

In Crawl space 1, the values for temperature and RH exceeded all growth limit curves on several occasions, and on all materials there was mould growth. Even in Attic 3, measured points were repeatedly above all curves. Established growth was there found on plywood, chipboard and thin hardboard. The reason that mould did not grow on asphalt paper or the two types of plaster board is probably that the periods of conditions favourable for growth were not long enough, since the cumulative time that the limits for these materials were exceeded was less than one week, which was significantly less than the minimum required for the critical moisture level to be achieved in a laboratory environment. In Crawl space 3 and Attic 1, growth of mould was expected on all materials on which there was mould growth in the laboratory, since several points of temperature and $\mathrm{RH}$ were above the growth limit curves. Although the cumulative time that this occurred was greater than in Attic 3, it was still less than was required for critical mould growth in laboratory conditions, which may explain why mould did not grow on materials other than plywood in Crawl space 3 or on plywood and chipboard in Attic 1. However, the values for chipboard in Crawl space 3 are on the boundary of the reference time from the laboratory tests.

In Crawl space 2, measured values only exceeded growth curves for plywood, which was also the only material on which mould grew. Even in Attic 2, mould was only expected to grow on plywood, though no growth was observed here. Again, the reason might be that the favourable conditions did not last long enough; in this case, the cumulative time that the lower growth limit curve was exceeded was less than one week. No values were measured above the upper curve at all. In practice, it is therefore possible that the actual critical value for mould growth was never exceeded, since it may lie somewhere between the upper and the lower curve.

Using the cumulative time for conditions that was favourable is a simplified method of considering the conditions that affect

Table 4

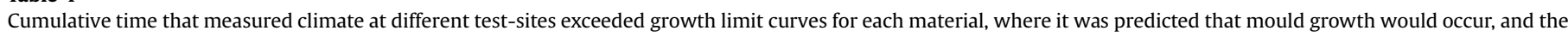
time before critical moisture levels was reached in the laboratory tests.

\begin{tabular}{|c|c|c|c|c|c|c|c|c|c|c|}
\hline & \multicolumn{2}{|l|}{ Crawl space 3} & \multicolumn{2}{|l|}{ Attic 1} & \multicolumn{2}{|l|}{ Attic 2} & \multicolumn{2}{|l|}{ Attic 3} & \multicolumn{2}{|c|}{$\begin{array}{l}\text { Time (weeks) in the } \\
\text { laboratory before } \\
\text { critical moisture } \\
\text { level was reached }\end{array}$} \\
\hline & $\begin{array}{l}\text { Time (weeks) } \\
\text { over lower } \\
\text { curve }\end{array}$ & $\begin{array}{l}\text { Times (weeks) } \\
\text { over upper } \\
\text { curve }\end{array}$ & $\begin{array}{l}\text { Time (weeks) } \\
\text { over lower } \\
\text { curve }\end{array}$ & $\begin{array}{l}\text { Weeks (weeks) } \\
\text { over upper } \\
\text { curve }\end{array}$ & $\begin{array}{l}\text { Time (weeks) } \\
\text { over lower } \\
\text { curve }\end{array}$ & $\begin{array}{l}\text { Weeks (weeks) } \\
\text { over upper } \\
\text { curve }\end{array}$ & $\begin{array}{l}\text { Time (weeks) } \\
\text { over lower } \\
\text { curve }\end{array}$ & $\begin{array}{l}\text { Weeks (weeks) } \\
\text { over upper } \\
\text { curve }\end{array}$ & $10^{\circ} \mathrm{C}$ & $22{ }^{\circ} \mathrm{C}$ \\
\hline Plywood & & & & & 0.3 & 0.0 & & & $11-12$ & $4-5$ \\
\hline Chipboard & 8.3 & 3.0 & & & & & & & $8-9$ & $3-4$ \\
\hline Thin hardboard & 3.0 & 0.9 & 1.9 & 1.4 & & & & & $10-11$ & $3-4$ \\
\hline $\begin{array}{l}\text { Exterior gypsum } \\
\text { board }\end{array}$ & 0.9 & 0.3 & 1.4 & 0.3 & & & 0.4 & 0.0 & 12 & $0-1$ \\
\hline $\begin{array}{l}\text { Wet room gypsum } \\
\text { paper board }\end{array}$ & 0.9 & 0.3 & 1.4 & 0.3 & & & 0.4 & 0.0 & $>12$ & $3-4$ \\
\hline Asphalt paper & 0.9 & 0.3 & 1.4 & 0.3 & & & 0.4 & 0.0 & $>12$ & $2-3$ \\
\hline
\end{tabular}




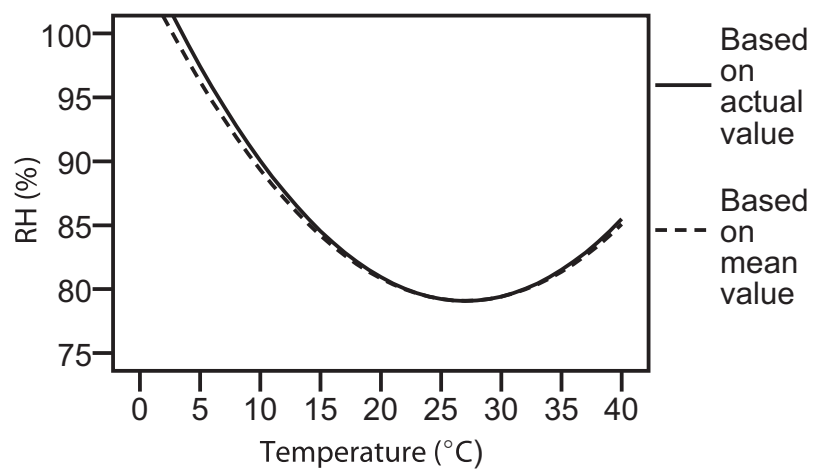

Fig. 7. Comparison between growth limit curves based on actual values of parameter $a$ for chipboard and based on values of parameter a calculated from the mean value of parameters a from all materials tested.

mould growth. These favourable conditions were followed by less favourable. How long they last, how far they are from the limits, and how rapid the changes between favourable and unfavourable conditions are affects the risk that mould growth will occur, as well as its extent over the surface and its growth rate $[10,17,18]$. This may explain why mould did not grow on chipboard in Crawl space 3, even though the cumulative time that favourable conditions were present was about the same as the reference values from the laboratory tests.

It is difficult to predict from laboratory tests on the material how long a material can withstand a particular environment without risk of mould growth, i.e. in addition to the time tested in the laboratory. The testing here was conducted over 2.5 years, but it is possible that testing for a longer time would increase the chance of mould developing (even on the material where no growth was observed in this study), since the cumulative time during which favourable conditions were present would be longer. Also, a material age with time, and contamination of the material can reduce resistance to mould growth $[19,20]$.

Assessing the critical moisture level of a material requires testing in a number of temperature and RH conditions. The test period and the number of test conditions must be limited for a commercial method to be economically justifiable and the results delivered within a reasonable time. The model used to produce growth limit curves for different materials requires testing to be carried out at two temperatures. However, an adjustment was made in this study so that, when testing at only one temperature, critical limits could be estimated for other temperatures with a maximum error of $2 \% \mathrm{RH}$. To reduce the time before mould growth occurs, the temperature should be relatively close to the optimum temperature for growth.

\section{Conclusions}

Overall, critical moisture levels, as determined in accelerated laboratory experiments under constant climatic conditions, match the results in real conditions where both temperature and relative humidity vary. If the combination of temperature and RH exceeds the growth limit curves calculated from the critical moisture levels, mould growth is expected. Further, when the duration of favourable conditions is not considered, the laboratory test results will not underestimate the risk of mould growth; the results will instead include a certain margin of safety.

If the expected temperature and $\mathrm{RH}$ in a construction is known, knowledge of the critical moisture levels of the materials and the calculated growth limit curves may therefore be used as tools when choosing the materials for the construction with minimum risk of mould growth.

\section{References}

[1] Ayerst G. The effects of moisture and temperature on growth and spore germination in some fungi. J Stored Prod Res 1969;5:127-41.

[2] Smith SL, Hill ST. Influence of temperature and water activity on germination and growth of Aspergillus restrictus and $\mathrm{A}$. versicolor. Trans $\mathrm{Br}$ Mycol Soc 1982;79:558-60.

[3] Magan N, Lacey J. Effect of water activity, temperature and substrate on interactions between field and storage fungi. Trans Br Mycol Soc 1984;82:83-93.

[4] Rowan J, Anderson JG, Smith JE, Clarke A, McLean RC, Kelly NJ, et al. Development of a computer programme for the prediction and control of mould growth in buildings using the ESP-r modelling system. Indoor Built Environ 1997;6:4-11.

[5] Sedlbauer K. Prediction of mould fungus formation on the surface of and inside building components. Fraunhofer Institute for Building Physics; 2001.

[6] Sedlbauer K. Prediction of mould growth by hygrothermal calculation. J Building Phys 2002;25:321-36.

[7] Johansson P, Ekstrand-Tobin A, Svensson T, Bok G. Laboratory study to determine the critical moisture level for mould growth on building materials. Int Biodeterior Biodegrad 2012;73:23-32.

[8] Vacher S, Hernandez C, Bartschi C, Poussereau N. Impact of paint and wallpaper on mould growth on plasterboards and aluminum. Build Environ 2010;45:916-21.

[9] David P. Phylloplane fungi: tolerance of hyphal tips to drying. Trans Br Mycol Soc 1982;79:174-8.

[10] Viitanen H, Bjurman J. Mould growth on wood under fluctuating humidity conditions. Mater Org 1995;29:27-46.

[11] Pasanen PO, Kolari S, Pasanen A-L, Kurnitski J. Fungal growth on wood surfaces at different moisture conditions in crawl spaces. In: Conference proceedings IAQ 2001 moisture, microbes, and health effects: indoor air quality and moisture in buildings. San Francisco, California: 2001.

[12] Bok G, Hallenberg N, Åberg O. Mass occurrence of Penicillium corylophilum in crawl spaces, south Sweden. Build Environ 2009;44:2413-7.

[13] Hagentoft C-E, Kalagasidis AS. Mold growth control in cold attics through adaptive ventilation. Validation by field measurements. Thermal performance of exterior envelopes of whole buildings XI. Florida; 2010.

[14] Fernicola V, Banfo M, Rosso L, Smorgon D. Investigation of capacitive-based relative humidity sensors and their stability at high temperature. Int J Thermophys 2008;29:1668-77.

[15] Singer JD, Willett JB. Applied longitudinal data analysis: modeling change and event occurrence. Oxford; New York: Oxford University Press; 2003.

[16] Hofbauer W, Kreuger N, Breuer K, Sedlbauer K, Schoch T. Mould resistance assessment of building materials - material specific isopleth-systems for practical application. Indoor Air; 2008. Copenhagen, Denmark: 2008. p. Paper ID: 465.

[17] Adan OCG. On the fungal defacement of interior finishes. PhD dissertation. Wageningen: University of Eindhoven; 1994.

[18] Pasanen A-L, Kasanen J-P, Rautiala S, Ikaheimoa M, Rantamaki J, Kaariainen H, et al. Fungal growth and survival in building materials under fluctuating moisture and temperature conditions. International Biodeterioration \& Biodegradation; 2000. p. 117-27.

[19] Grant C, Hunter CA, Flannigan B, Bravery AF. The moisture requirements of moulds isolated from domestic dwellings. Int Biodeterio 1989:259-84.

[20] Chang JCS, Foarde KK, VanOsdell DW. Assessment of fungal (Penicillium chrysogenum) growth on three HVAC duct materials. Environ Int 1996;22: 425-31. 